\title{
UNEXPECTED EXCESSIVE BLEEDING DURING OPERATION: ROLE OF ACETYL SALYCILIC ACID
}

\author{
D.W. Davies and D.J. Steward
}

UNEXPECTED, EXCESSIVE BLOOD LOSSES may occur during elective surgery. These losses are unexpected because the patient is not recognized as having a coagulopathy; excessive because they are greater than is usual during such surgical procedures. Such a situation during operation presents the anaesthetist with responsibility for rapid recognition, investigation, diagnosis and appropriate therapy of the conditon.

In The Hospital for Sick Children, Toronto, it has become apparent that, when unexpected excessive blood losses occur during operation, the cause in over 80 per cent of cases, has been acquired platelet dysfunction due to acetyl salycilic acid (A.S.A.) ingestion by the patient within one week prior to operation. This paper will outline the role of platelets in haemostasis and will discuss drug-acquired platelet dysfunction, the evaluation and investigation of unexpected and excessive blood loss during operation and will describe three cases of excessive bleeding due to the pre-operative ingestion of A.S.A. Recommendations will be made regarding drugs and elective surgery.

\section{Case reports}

Three children presenting for elective plastic surgery procedures who demonstrated unexpected and excessive pre-operative bleeding are presented. In none of these patients was a significant history of bleeding tendency or drug ingestion obtained pre-operatively. The case histories of these patients are listed in Table I.

\section{Haemostasis}

Haemostasis is achieved in three distinct stages; the vascular response, blood coagulation and organization of the blood clot. Normal numbers of functioning platelets either contribute to or are essential to each of these stages.

The vascular response to bleeding consists of the constriction of neighbouring vessels by local and reflex factors. This is enhanced by the release of platelet factors, primarily serotonin.

Blood coagulation is brought about by the cascading events of the autocontrolled interaction of the intrinsic and extrinsic systems of the coagulation process. These systems are both essential to ensure an adequate amount of active factor $V$, which is a mandatory factor in the conversion of factor II (Prothrombin) to active

D.W. Davies, F.R.C.P.(C), Staff Anaesthetist, The Hospital For Sick Children, Toronto, Assistant Professor, University of Toronto; D.J. Steward, F.R.C.P.(C), Anaesthetist-in-Chief, The Hospital For Sick Children, Toronto, Professor, Dept. of Anaesthesia, University of Toronto. Address reprint requests to: Dr. D.W. Davies, Department of Anaesthesia, The Hospital For Sick Children, 555 University Avenue, Toronto, Ontario, Canada M5G 1 X8. 
TABLE I

Summary of Three Cases of Unexpected, Excessive Bleeding During Operation Due to A.S.A. Platelet Dysfunction

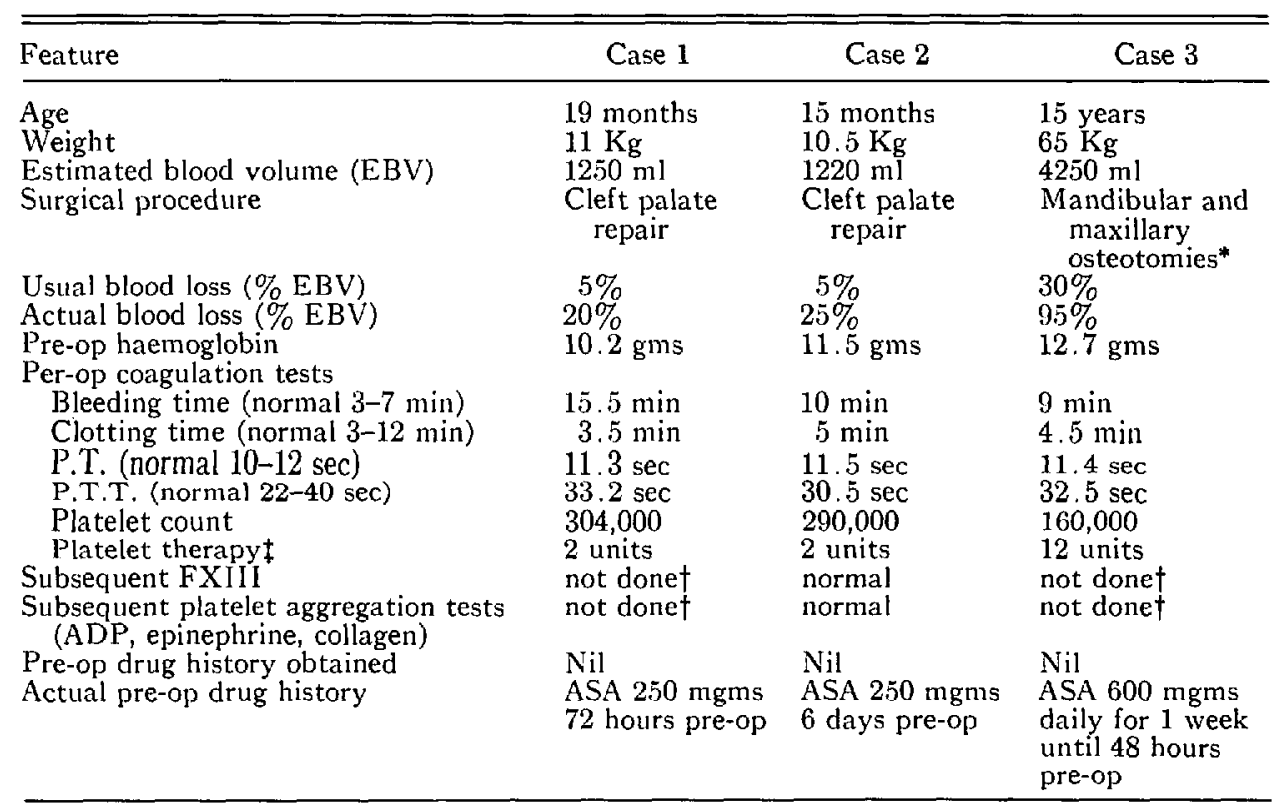

*With hypotensive anaesthetic techniques.

thave not attended for follow-up.

$\ddagger$ Platelet therapy usually calculated as 1 unit of platelet concentrate per $5 \mathrm{Kg}$ body weight.

factor II (Thrombin). The active factor II is essential in the conversion of factor I (fibrinogen) to active factor Ia (fibrin), the fundamental structural constituent of the blood clot.

Following the formation of blood clot, its organization into a retractable tenacious plug is necessary if it is to be an effective haemostat.

The stages of the coagulation process are schematically represented in Figure 1.

\section{Platelet function and haemostasis}

Platelets have an average life of ten days and a half-life of three days. Platelet functions in haemostasis are primary aggregation, release of platelet constituents, secondary aggregation and clot retraction. Platelet release is essential for effective haemostasis.

Primary aggregation of platelets is induced by contact with subendothelial components of damaged vessels. Other factors which enhance aggregation include collagen, $\alpha$ and $\beta$ catechols and serotonin. This primary aggregation is followed by the release of platelet constituents including adenine diphosphate (ADP) which induces a second phase of platelet aggregation and forms the primary haemostatic plug. Platelet factor $3\left(\mathrm{PF}_{3}\right)$ is also released and catalyzes the generation of thrombin, which effects the conversion of fibrinogen to form fibrin, which becomes the clot matrix. Thrombin is a potent platelet releasing agent and enhances the platelet cycle. The aggregated platelets also release thrombasthenin, a contractile 


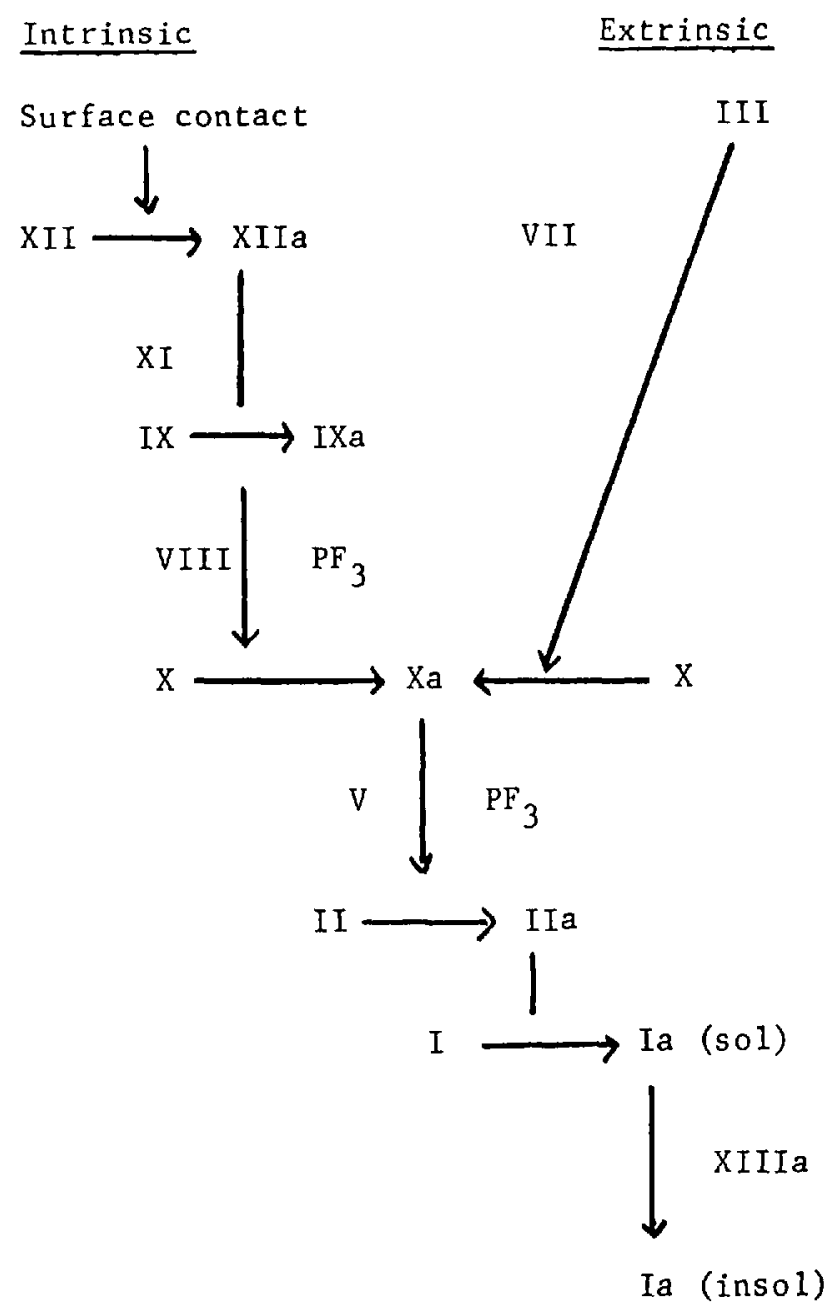

Figure 1. Coagulation factors and haemostasis.

protein that induces the retraction of insoluble fibrin to give the final effective haemostatic clot.

The role of platelets in haemostasis is shown schematically in Figure 2.

\section{Drug-induced platelet dysfunction}

A wide range of drugs adversely affect platelet function (Table II). The degree of dysfunction depends on many interrelated factors and is subject to individual variation. The exact nature of the dysfunction is not known for all drugs but is usually one of inhibition of ADP release; but the end result is always one of diminished platelet aggregation. In the case of aspirin and other non-steroid anti-inflammatory agents the platelets are prevented from releasing ADP. Consequently the platelets are unable to cause the secondary aggregation so necessary for successful haemostasis. This defect can arise following one dose of $300 \mathrm{mgm}$ of A.S.A. and will persist for the life of the affected platelets. Aminocetaphen is free of this property. 


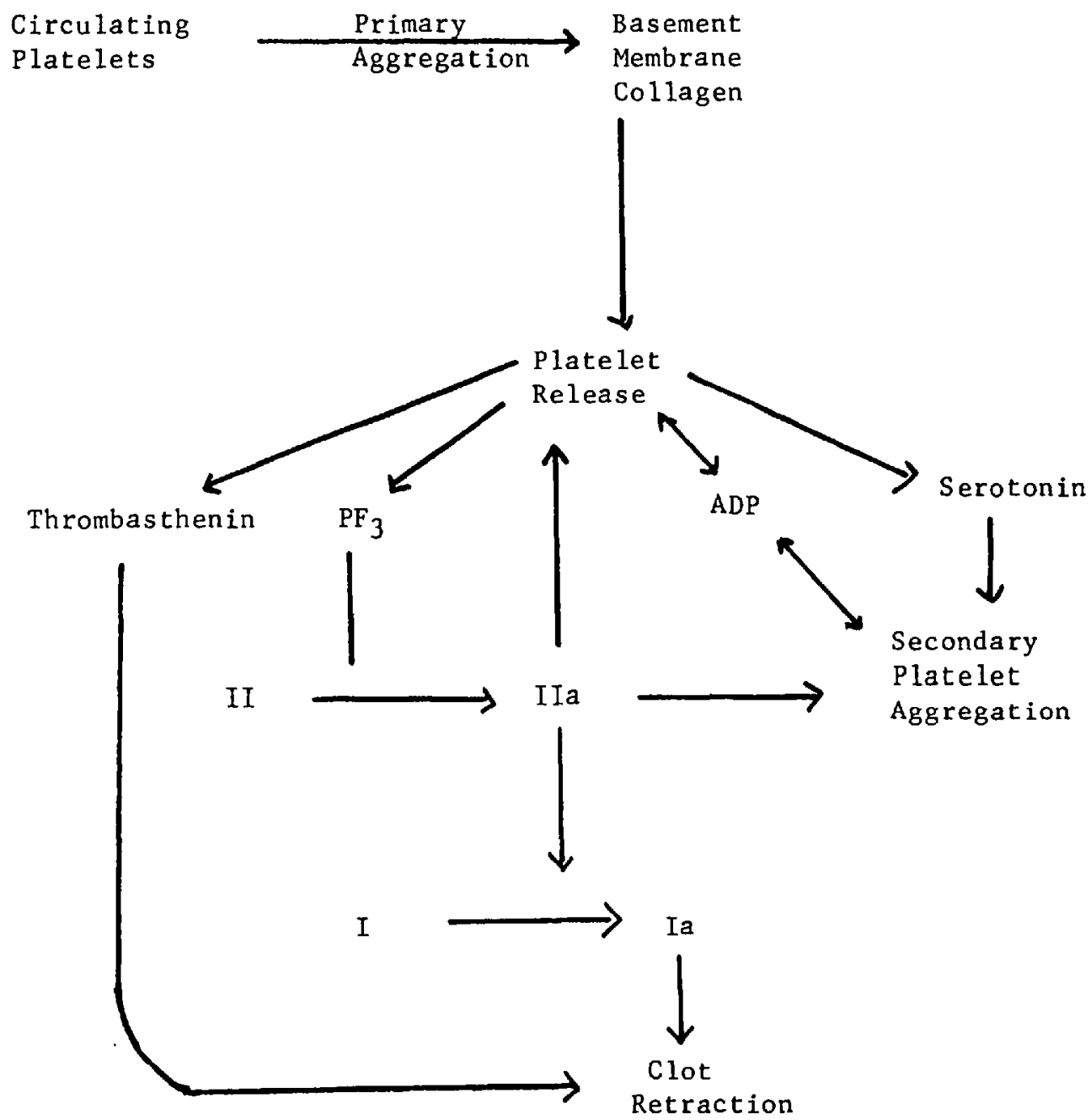

Figure 2. The role of platelets in haemostasis.

\section{Unexpected excessive bleeding during operation}

For practical purposes unexpected excessive bleeding during operation can be classified by aetiology as surgical, anaesthetic or haematological.

Surgical causes are primarly inadequate technical haemostasis. Anaesthetic causes may include too light a depth of anaesthesia, hypercarbia, hypoxaemia, inappropriate posturing of the patient, and venous obstruction. Haematological causes may be consequent to blood transfusion, fibrinolysis or platelet dysfunction.

Blood transfusion can cause coagulopathies in two ways. Massive transfusion of bank blood can cause a dilution of coagulation factors, particularly of platelets, factor $V$ and factor VIII and fibrinogen. Mismatched transfusion can cause a consumption of similar coagulation factors.

Fibrinolysis may occur during operation either as a primary or secondary phenomenon. Primary fibrinolysis is thought to occur rarely if at all. Secondary 
TABLE II

Drugs Which Cause Platelet Dysfunction

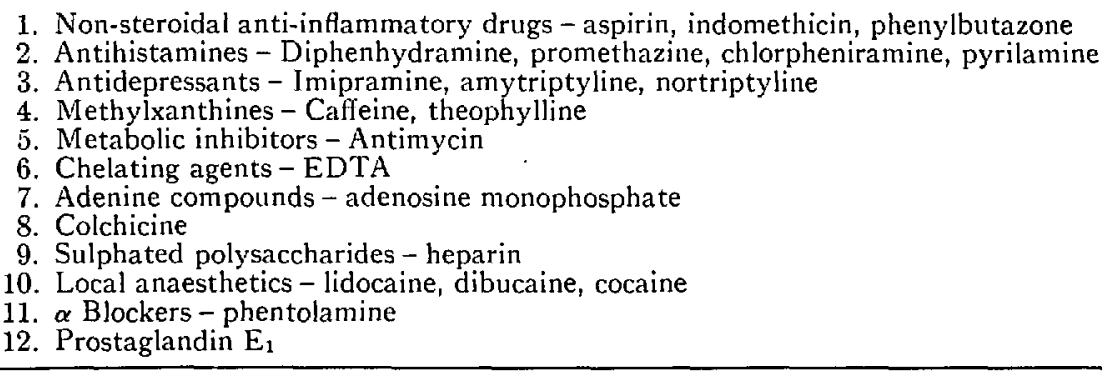

fibrinolysis is a consequence of disseminated intravascular coagulopathy which may be associated with many clinical entities.

Platelet dysfunction may be hereditary or acquired. The hereditary ones include thrombasthenia (Glanzmann's disease), thrombocytopathy, Von Willebrand's disease, and hereditary afibrinogenaemia. These should be documented in the patient history and are, therefore, outside the scope of this paper. The acquired platelet dysfunctions include those induced by myeloproliferative disease, uraemia, scurvy and various drugs. Various states of thrombocytopenia should also be apparent and should be part of the pre-operative history.

\section{Investigation of unexpected, excessive bleeding during operation}

At the outset one has to eliminate surgical and anaesthetic causes. If then the problem persists, one has to distinguish between coagulopathies due to consumption or dilution of coagulation factors and those due to platelet dysfunction. For practical purposes the problem can be adequately screened by the following tests: bleeding time (B.T.), clotting time (C.T.), prothrombin time (P.T.), partial thromboplastin time (P.T.T.), platelet count and estimation of fibrin split products (F.S.P.), haematocrit and urinalysis.

Mismatched transfusion should be readily discernible if the urine and the plasma of the haematocrit (a micro-haematocrit can be done in the operating room with capillary tube and centrifuge) are pink with the haemoglobin released from haemolysed red blood cells.

The bleeding time can also be readily determined in the operating room. The bleeding time is the most reliable indicator of adequate platelet function. A sphygomanometer cuff is inflated about the arm and maintained at $40 \mathrm{~mm} \mathrm{Hg}$ and three incisions $1 \mathrm{~mm}$ deep are made separately on the flexor aspect of the forearm. The bleeding from these sites is blotted away by capillary action using gauze or a filter paper at one-minute intervals until no bleeding occurs. This normally is less than seven minutes (average of the three sites). Any time in excess of this denotes inadequate platelet function. The haematology laboratory can then further differentiate the nature of the problem with the P.T., P.T.T., F.S.P. and platelet count estimations. The P.T. is a measure of the adequacy of the extrinsic system and the P.T.T. of the intrinsic system. Dilution of coagulation factors by massive trans- 
TABLE III

Investigations for Unexpected Excessive Bleeding During Operation

\begin{tabular}{lllll}
\hline \hline \multicolumn{1}{c}{ Test } & $\begin{array}{l}\text { Mismatched } \\
\text { Transfusion }\end{array}$ & Dilutional & Consumptive & $\begin{array}{l}\text { Platelet } \\
\text { dysfunction }\end{array}$ \\
\hline Bleeding time & Normal & Normal & Normal & Prolonged \\
Clotting time & Prolonged & Prolonged & Prolonged & Normal \\
P.T. & Increased & Increased & Increased & Normal \\
P.T.T. & Increased & Increased & Increased & Normal \\
F.S.P. & Present & Absent & Present & Absent \\
Platelets & Moderately & Severely & Moderately & Normal \\
& decreased & decreased & decreased & Normal \\
Serum & Pink & Normal & Normal & Normal \\
Urine & Pink & Normal & Normal & Normal \\
\hline
\end{tabular}

fusion will usually show an increase in the P.T. and P.T.T. and a fairly severe decrease in platelets with an increase in clotting time, but a normal bleeding time.

Consumptive coagulopathies will invariably show a prolonged P.T. and P.T.T. and a mild to moderate reduction in platelets, an increase in the clotting time, a normal bleeding time and the presence of F.S.P.

Platelet dysfunctions, such as A.S.A. affected platelets, will have a prolonged bleeding time in the presence of an otherwise normal coagulation screen. Sophisticated platelet function tests of aggregation and release are beyond the scope of this paper and unnecessary for the diagnosis and therapy of the immediate problem. These are summarized in Table III.

\section{Conclusion}

With an understanding of the mechanisms of haemostasis and of the role of platelets, the aetiology of unexpected, excessive blood loss during surgery can usually be identified.

At The Hospital for Sick Children, Toronto, over 80 per cent of such problems were found to be due to drug-induced platelet dysfunction, usually due to A.S.A. or A.S.A. containing cold medications. If these drugs were self-prescribed they were usually not considered as medications by the patients or their parents, and thus no history of drug ingestion was obtained. An adequate history including specific questioning about A.S.A. intake during the week before elective surgery is necessary if those patients who are at risk are to be identified. These patients can then have a pre-operative bleeding time done and if this is found to be prolonged can have their operations deferred until they are free of drug-induced platelet abnormalities.

For operations during which adequate haemostasis is difficult to obtain, such as osteotomies, cleft palate repairs, pharyngoplasties, dental surgery, intra-occular surgery and tonsillectomies, a history of A.S.A. ingestion (or drugs with a similar platelet effect) within one week of operation in the presence of a prolonged bleeding time is a contraindication to surgery.

The practice of good preventive medicine in this matter can significantly reduce patient morbidity and the demand on the services and products of the blood transfusion service. 


\section{RÉSUMÉ}

Nous avons trouvé dans notre milieu (le Sick Children de Toronto) que plus de 80 pour cent des cas de saignement excessif inattendu en cours de chirurgie, sont causés par une dysfonction plaquettaire, le plus souvent secondaire à l'ingestion d'acide acétyl solycilique ou de médication antigrippale contenant de l'acide acétyl solycilique.

Trois cas illustratifs sont présentés, de même qu'une liste des médicaments susceptibles d'amener une dysfonction plaquettaire.

La décision de la prise de ces médicaments, à domicile, relève le plus souvent du malade lui-même ou de ses parents. Aussi, il sera nécessaire de s'informer spécifiquement si le malade a pris de l'aspirine ou une médication antigrippale dans la semaine précédant l'intervention, si l'on veut identifier les malades susceptibles de présenter des problèmes.

En cas de réponse positive, le temps de saignement devrait être déterminé et s'il est prolongé, l'intervention devrait être retardée jusqu'au retour à la normale. Nous considérons qu'on temps de saignement prolongé constitue une contreindication à une intervention immédiate dans les cas d'interventions où l'hémostase est particulièrement difficile, comme une ostéotomie, une réparation de fente palatine, une pharyngoplastie, une chirurgie ophtalmique, dentaire ou amygdalienne.

Une telle politique contribue à réduire la morbidité et à diminuer les demandes d'examens et de produits aux services de banques de sang.

\section{REFERENCES}

1. Mustand, J.F, \& PAскнам, M.A. Factors influencing platelet function: adhesion, release and aggregation. Pharm. Rev. 22(2): 97-187 (1970).

2. Rossi, E.C. \& Green, D. Disorders of platelet function. Med. Clin. of North America $56(1): 35-46$ (1972).

3. Milss, D.C.B. Drugs that effect platelet behaviour. Clinics in Haematology 1(2): 295-305 (1972).

4. Blood transfusion and blood products. Clinics in Haematology 2(1) (1973).

5. Blood coagulation and fibrinolysis in clinical practice. Clinics in Haematology 5(1) (1976). 